\title{
Are We Learning Enough Pathology in Medical School to Prepare Us for Postgraduate Training and Examinations?
}

\author{
Emma Marsdin ${ }^{1}$ and Seema Biswas ${ }^{2}$ \\ ${ }^{1}$ Department of Urology, Derriford Hospital, Derriford Road, Crownhill, Plymouth, Devon PL6 8DH, UK \\ ${ }^{2}$ Department of Surgery, Ziv Hospital, Safed, 13000 Galilee, Israel
}

Correspondence should be addressed to Seema Biswas; seemabiswas@msn.com

Received 16 December 2012; Accepted 23 January 2013

Academic Editor: Femi Oyebode

Copyright (C) 2013 E. Marsdin and S. Biswas. This is an open access article distributed under the Creative Commons Attribution License, which permits unrestricted use, distribution, and reproduction in any medium, provided the original work is properly cited.

\begin{abstract}
Medical schools responded to the first publication of Tomorrow's Doctors with an abbreviated syllabus and a reduction in didactic teaching hours. Prescribing errors, however, have increased, and there is a perception amongst clinicians that junior doctors know less about the pathological basis of disease. We asked junior doctors how useful they thought their undergraduate teaching in pathology had been in their postgraduate training. We had 70 questionnaire responses from junior doctors within a single deanery and found that although almost every doctor, $n=61$ (96\%), thought that pathology formed a major component of their postgraduate exams, most, $n=47$ (67\%), thought that their undergraduate teaching left them unprepared for their postgraduate careers, and they had to learn basic principles, as they revised for postgraduate exams. Few used a pathology text for learning, most doctors, $n=64$ (91\%), relying on question and answer revision resources for exam preparation. Perhaps, as revision materials are used so widely, they might be adapted for long-term deep learning, alongside clinical work. This presents an opportunity for pathologists, deaneries, royal colleges, and publishing houses to work together in the preparation of quality written and online material readily accessible to junior doctors in their workplace.
\end{abstract}

\section{Introduction}

There have been two revisions since the original publication of the GMC's Tomorrow's Doctors in 1993 [1-3] when medical schools that revised their syllabus and curriculum to reduce the volume of facts medical students were required to learn and to reduce the amount of didactic teaching in favour of self-directed learning $[4,5]$. Two subjects that have suffered are clinical pharmacology and pathology, and in subsequent revisions Tomorrow's Doctors have sought to redress this.

In the wake of increasing prescribing errors [6], medical schools and some NHS Trusts seek to teach and test clinical pharmacology and prescribing [7], and a national prescribing exam is set to be launched in $2014[8,9]$. What about pathology? Several authors lament that the reduction in taught courses in histopathology and chemical pathology has resulted in a generation of junior doctors who do not really understand what is wrong with their patients or how to interpret the results of investigations $[4,5,10,11]$. Postgraduate training assumes a certain level of knowledge; however, membership exams rely on a grounding in pathology that they examine in detail. So how well do their undergraduate courses prepare junior doctors preparing for membership exams and life on the ward?

We performed a study asking doctors about to sit their exams and doctors who had just attained their membership, how well their undergraduate pathology teaching prepared them for their clinical work, and what they used to prepare for the pathology component of their postgraduate exams.

\section{Study Methods}

A questionnaire study was undertaken between January 2011 and March 2011 where 70 consecutive trainees within one UK deanery (Oxford) were handed a single-page questionnaire to complete in the hospital where the author works and at regional teaching sessions. Each potential respondent was asked where they had completed their undergraduate medical 


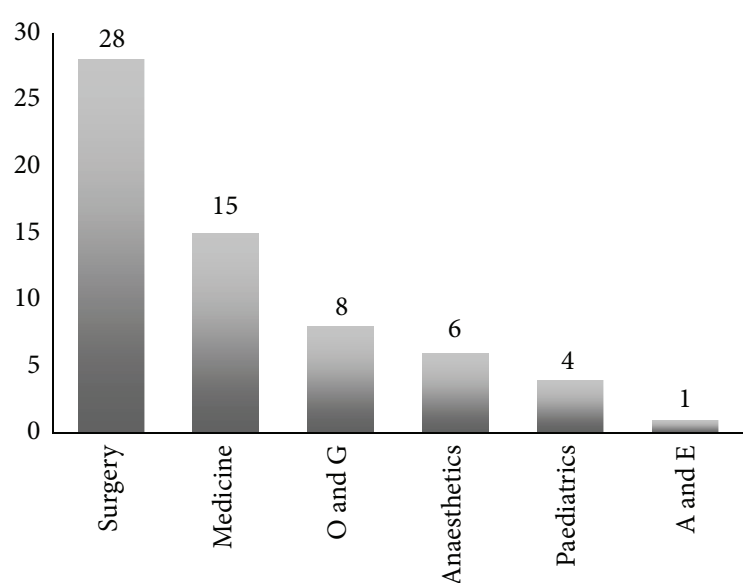

FIGURE 1

training, and only graduates of UK medical schools were asked to complete a questionnaire, as we sought to evaluate undergraduate pathology teaching in the UK only.

Each respondent approached gave verbal consent to complete the questionnaire and completed it themselves. Details of name, grade, and specialty were included, and the trainee sample included a range of different specialities including surgery, medicine, anaesthetics, paediatrics, obstetrics, and gynaecology.

\section{Results}

Results were collated from all completed questionnaires $(n=$ 70).

Figure 1 shows the specialities of trainees who completed the questionnaire. The results show that trainees in all specialities believe that pathology remains a significant component of the membership exams, $n=61$ (87\%) (Figure 1). The majority, $n=47$ (67\%), of trainees felt that their undergraduate courses had not prepared them for their membership exams, and that they were disadvantaged in having to learn pathology from first principles rather than build on the basics they hoped to know already. Several doctors claimed not to have had a distinct pathology taught course in medical school. Although most students, $n=60$ (86\%), kept undergraduate notes they had, very few $(n=6$, 9\%) actually used these notes as a basis for preparation for their membership exams, as they did not cover specific topics in sufficient detail, and exam revision aids were perceived to be a more comprehensive source for exam preparation.

We asked exactly what materials doctors preparing for their exams did use as an alternative or in addition to their undergraduate pathology notes. Most doctors, $n=64$ (91\%), relied heavily on published question and answer revision material (both in written form and online) rather than pathology texts (Figure 2).

e-Path is a web-based educational resource to support medical and healthcare science trainees. It is delivered in partnership by the Royal College of Pathologists and eLearning for Healthcare (e-LfH) [12]. Few junior doctors

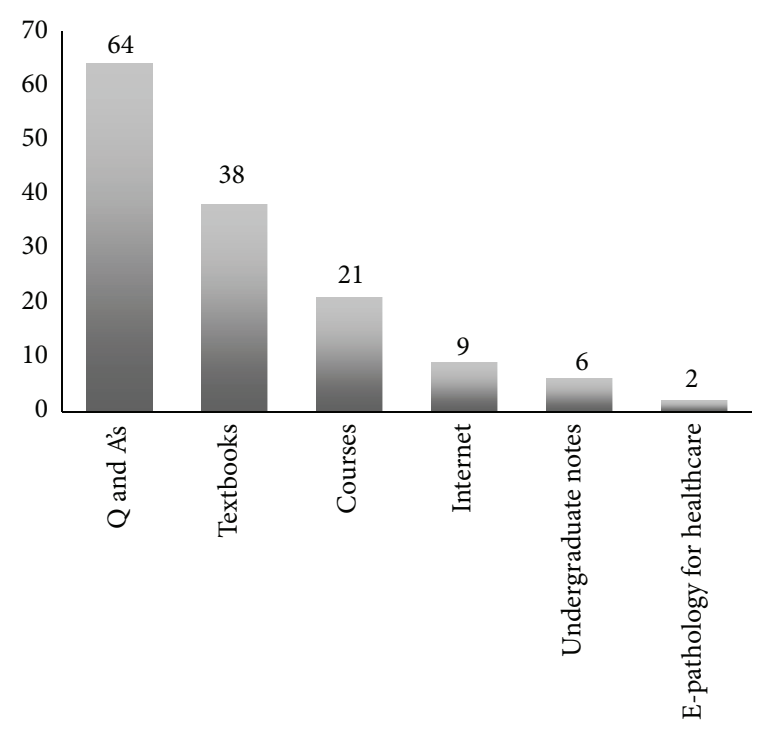

Figure 2

were aware of the existence of the pathology e-LfH website, $n=9(13 \%)$. Only 2 trainees (3\%) used this as a revision aid. Most doctors surveyed were unaware that this was readily accessible at work.

\section{Discussion}

That a sound knowledge of pathology is essential to clinical practice is in no doubt. The surgical specialties most certainly require this in every aspect of practice. This is reflected in the membership examination of the Royal College of Surgeons (MRCS), an entry requirement into formal surgical training, where pathology comprises one-third of the examination and is examined separately in the viva voce component and in the membership examination of the Royal College of Obstetrics and Gynaecology (MRCOG) where pathology comprises up to one-fifth of the clinical papers. Trainees in nonoperative specialties, however, whether interpreting results or discussing management decisions in multidisciplinary meetings, also need to learn and understand pathology and are at a huge disadvantage in routine clinical work if they are unable to appreciate the significance of pathological findings and the natural history of disease.

Pathologists and clinicians have documented their experience of dealing with doctors who know much less pathology than junior doctors knew in the past $[4,5,8-11]$, but it is rare to hear from the junior doctors themselves. The perception amongst the trainees we sampled was that they did believe that pathology formed a significant part of their postgraduate learning. Just how helpful their undergraduate pathology learning to their postgraduate training depends, of course, on the nature of the undergraduate course and their own learning and retention of this material. Although we asked exactly where each respondent had trained, we did not correlate this with information about the exact nature of the course and accept that there might be considerable variation in the undergraduate teaching and learning of pathology 
across the UK. Nevertheless, the postgraduate syllabus for each specialty is standardized, and it is at this level that gaps in undergraduate knowledge require further study to meet national examination standards.

One source of postgraduate learning is published revision material. Good exam revision resources, however, though widely available, are unlikely, on their own, to form a fundamental understanding of the pathological basis of disease. Effective undergraduate teaching and learning is key and sets the precedent for postgraduate self-study using local and college facilities integrated with clinical medicine. Where there might be gaps in undergraduate learning, postgraduate learning material should be comprehensive and cover pathology from first principles.

Later versions of Tomorrow's Doctors [2, 3] have sought to rebalance the emphasis on the core curriculum and increase the amount and details of pathology taught in medical school, but many pathology departments experienced crippling cuts in staffing and funding about 15 years ago, and meeting the increasing need for teaching may present a challenge.

There is a dependence on question and answer revision aids. Over $90 \%$ of trainees use these, and while superficial learning or cramming just before exams is effective to some extent in terms of exam success, it is unlikely that this would form the basis of integrated clinical learning. Perhaps revision resources may be adapted for more long-term use throughout the junior doctor years to provide integrated learning alongside clinical experience? This would require collaboration between deaneries, the royal colleges, and major publishing houses.

Take home message: our study indicates that learning pathology remains important in training in all specialties and postgraduate exams. Doctors need to be able to rely on their undergraduate learning and use quality resources that are easily available at work, and that they can integrate with their clinical activity. Their dependence on revision resources begs the question that perhaps revision resources should be developed in collaboration with pathologists, the specialty colleges, and experienced teachers.

\section{Authors' Contribution}

E. Marsdin circulated the questionnaires, collected them, and wrote the first draft of the paper. S. Biswas proposed the study and edited the paper.

\section{References}

[1] General Medical Council, Tomorrow's Doctors. Recommendations on Undergraduate Medical Education, GMC, London, UK, 1993.

[2] General Medical Council, Tomorrow's Doctors. Recommendations on Undergraduate Medical Education, GMC, London, UK, 2003.

[3] General Medical Council, Tomorrow's Doctors. Recommendations on Undergraduate Medical Education, GMC, London, UK, 2009.
[4] R. Marshall, N. Cartwright, and K. Mattick, "Teaching and learning pathology: a critical review of the English literature," Medical Education, vol. 38, no. 3, pp. 302-313, 2004.

[5] K. Mattick, R. Marshall, and J. Bligh, "Tissue pathology in undergraduate medical education: atrophy or evolution?” Journal of Pathology, vol. 203, no. 4, pp. 871-876, 2004.

[6] T. Dornan, D. Ashcroft, H. Heathfield et al., "An in depth investigation into causes of prescribing errors by foundation trainees in relation to their medical education. EQUIP study," Final Report, General Medical Council, London, UK, 2009.

[7] M. Tobaiqy, J. McLay, and S. Ross, "Foundation year 1 doctors and clinical pharmacology and therapeutics teaching. A retrospective view in light of experience," British Journal of Clinical Pharmacology, vol. 64, no. 3, pp. 363-372, 2007.

[8] L. O'Shaughnessy, I. Haq, S. Maxwell, and M. Llewelyn, "Teaching of clinical pharmacology and therapeutics in UK medical schools: current status in 2009," British Journal of Clinical Pharmacology, vol. 70, no. 1, pp. 143-148, 2010.

[9] J. K. Aronson, "Editors' view: a prescription for better prescribing," British Journal of Clinical Pharmacology, vol. 61, no. 5, pp. 487-491, 2006.

[10] T. A. Gray and A. El-Kadlki, "Filling the gaps in undergraduate teaching of clinical biochemistry," Journal of Clinical Pathology, vol. 63, pp. 99-101, 2010.

[11] Freedman and D. B., "Is the medical undergraduate curriculum "fit for purpose"?" Annals of Clinical Biochemistry, vol. 45, pp. $1-2,2008$.

[12] 2012, http://www.e-lfh.org.uk/projects/epath/index.html . 

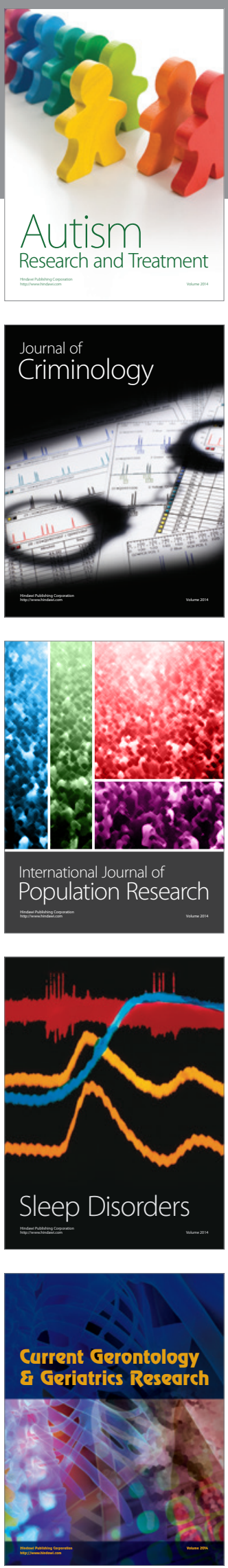
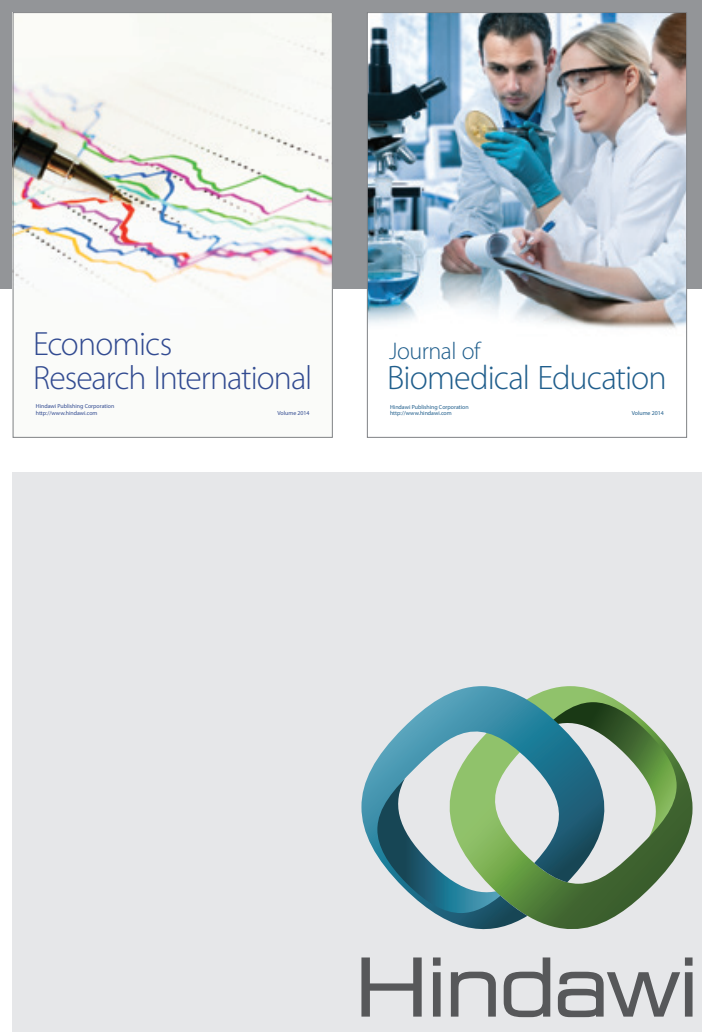

Submit your manuscripts at

http://www.hindawi.com
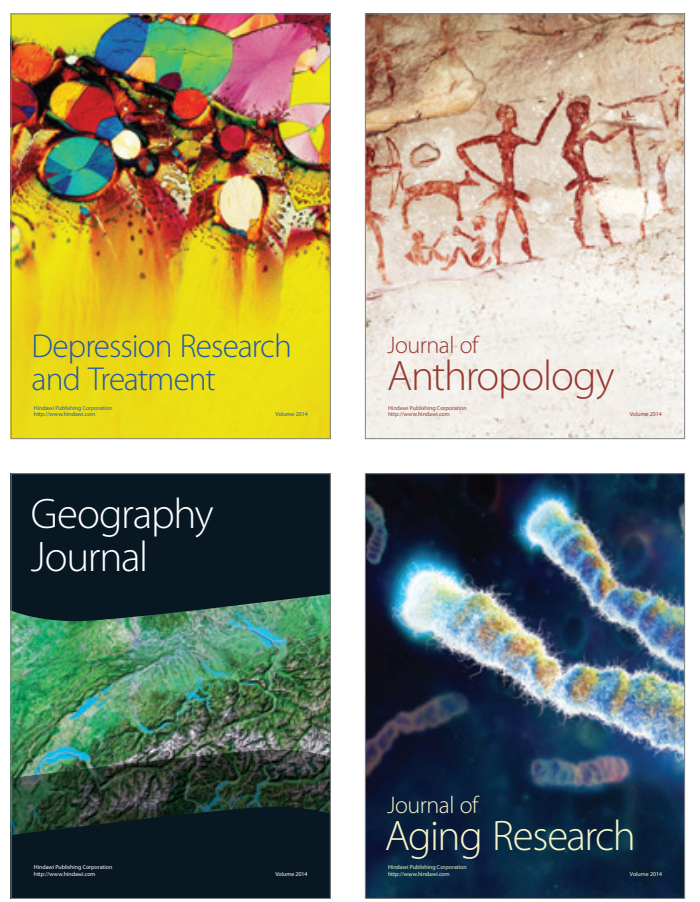
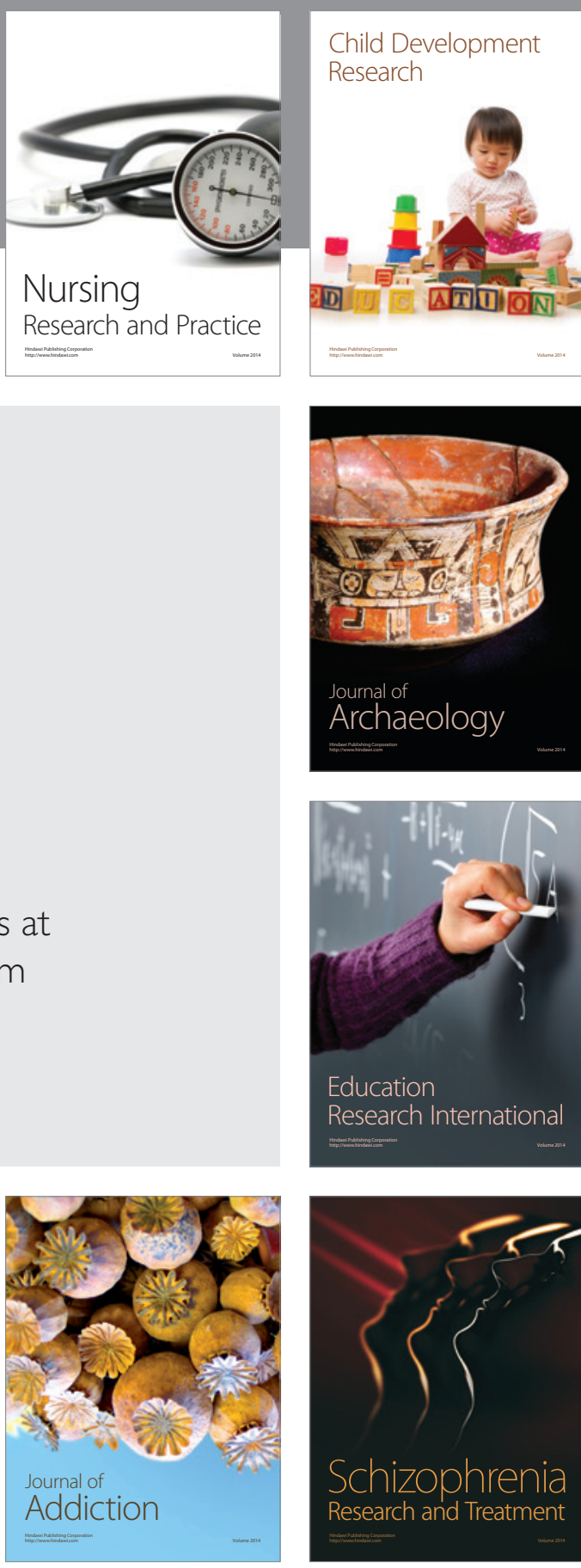

(D)
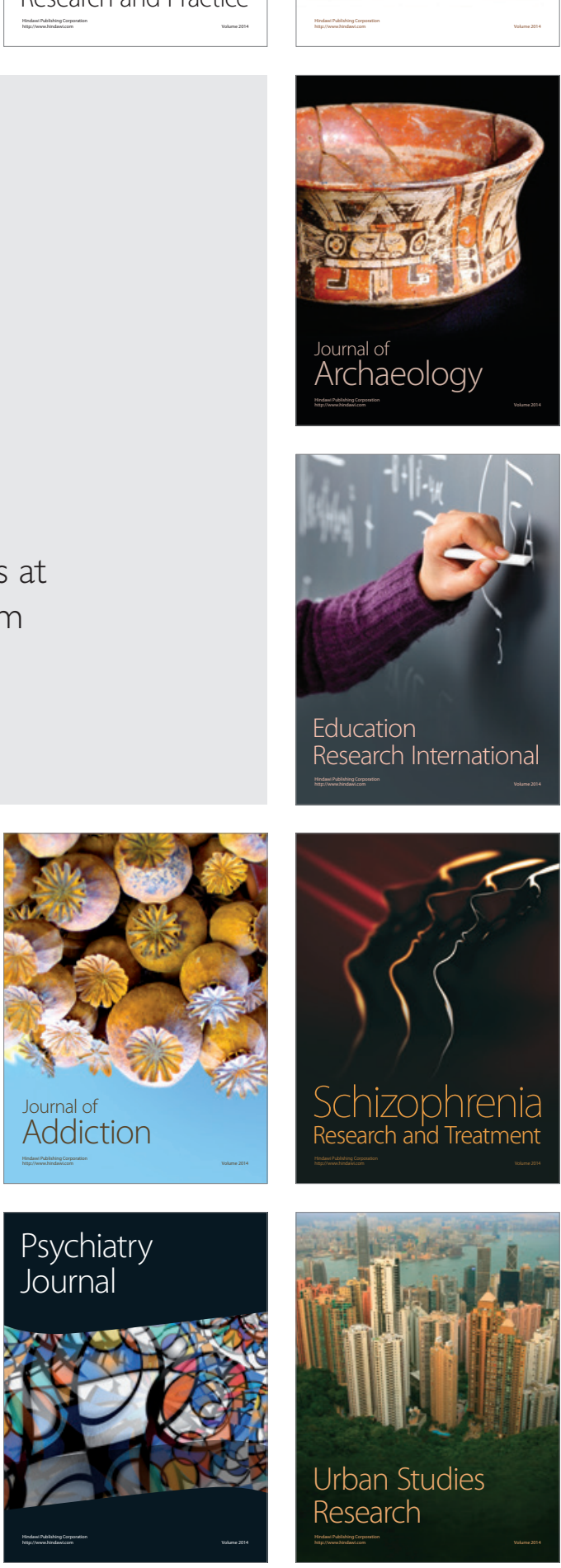